Савцова Анна Валерьевна, Паценко Ольга Николаевна, Анимукова Диана Муаедовна

\title{
РОЛЬ УПРАВЛЕНИЯ ФЕДЕРАЛЬНОГО КАЗНАЧЕЙСТВА РЕГИОНА В ИСПОЛНЕНИИ БЮДЖЕТА СУБЪЕКТА ФЕДЕРАЦИИ ПО ДОХОДАМ
}

В статье рассматривается роль Управления Федерального казначейства по Кабардино-Балкарской Республике в исполнении бюджета региона по доходам, проводится анализ доходной части бюджета республики, приводятся причины сложивиейся динамики, рассматриваются направления укрепления доходной базы бюджета республики, включая применение современных казначейских технологий, цифровизации.

Ключевые слова: УФК по Кабардино-Балкарской Республике, доходы бюджета Кабардино-Балкарской Республики, анализ структуры и динамики, размещение временно свободньх остатков средсть, финансовые инструменты, депозиты, сделки РЕПО, иифровизация.

\section{Anna Savtsova, Olga Patsenko, Diana Animucova \\ THE ROLE OF REGIONAL DEPARTMENT OF FEDERAL TREASURY \\ IN THE IMPLEMENTATION OF THE BUDGET OF THE SUBJECT OF FEDERATION INCOME}

In article discusses the role of the regional department of the Federal Treasury in Kabardino-Balkar Republic in the execution of the budget of the region on income is considered, the analysis of the revenue part of the budget of the Republic is carried out, the reasons of the current dynamics are given, the directions of strengthening of the revenue base of the budget of the Republic, including the use of modern Treasury technologies, digitalization are considered.

Key words: regional department of Federal Treasury in Kabdardino-Balkar Republic, budget revenues of the Kabardino-Balkar Republic, analysis of the structure and dynamics, placement of temporarily free balances, financial instruments, deposits, REPO transactions, digitalization.

Bведение / Introduction. В соответствии с бюджетным законодательством, в Российской Федерации введена казначейская система исполнения бюджетов, то есть Казначейством России осуществляется кассовое обслуживание исполнения бюджетов. Современная деятельность Федерального Казначейства включает массу актуальных целей для бюджетного процесса: ведение и обслуживание государственных информационных систем, предварительный, оперативный и текущий контроль операций участников бюджетного процесса, учет и распределение поступлений и т. д. В качестве одной из самых, на наш взгляд, важнейших следует выделить управление остатками ресурсов на едином бюджетом счете, преумножение их с помощью размещения в финансовые инструменты, причем с привлечением к данному инструменту территориальных органов Федерального казначейства.

Ранее фундаментальные основы управления казначейским счетом были рассмотрены в работах ученых С. Ю. Витте, А. Н. Козырина, С. А. Котляровского, а также зарубежных авторов С. Л. Брю, Дж. М. Кейнса и других. Среди современных исследователей бюджетного процесса, в частности исполнения бюджета по казначейскому типу, были выделены труды Л. А. Агузаровой, Р. Е. Артюхина, В. А. Комягина, Т. Г. Маковник, С. Е. Прокофьева, Н. А. Размановой, Н. Х. Токаева и др. Управление денежными потоками, финансовые инструменты и механизмы поддержки ликвидности в государственной и банковской сферах достаточно полно и подробно исследовались М. В. Аликаевой, Р. Е. Артюхиным, В. Ф. Жуковым, И. Я. Лукасевичем, В. А. Челноковым, Дж. Ф. Синки-мл. 
Несмотря на наличие пространного числа изданий, многие аспекты поставленной проблемы нуждаются в дальнейшем разрешении. Прежде всего наблюдается недостаток исследований, предусматривающих комплексное рассмотрение использования финансовых инструментов управления свободными ресурсами в бюджетной сфере. Важнейшим является вопрос об отсутствии возможности управления ликвидностью средств на счетах всех региональных и местных бюджетов.

Maтериалы и методы / Materials and methods. Как уже отмечалось, на сегодняшний день отсутствует возможность управления ликвидностью средств на счетах региональных бюджетов. Рассмотрим проблемы исполнения доходной части бюджета на примере УФК по КБР, которое является территориальным органом Федерального казначейства, созданным в границах Кабардино-Балкарской Республики, находится в подчинении Федерального казначейства. Управление взаимодействует с территориальными органами исполнительной власти региона. Исполнение Кабардино-Балкарской Республикой возложенных на нее как на субъект Российской Федерации обязанностей по обеспечению эффективного социально-экономического развития территории напрямую зависит от величины доходной части ее бюджета. Недостаточность поступающих в республиканский бюджет денежных средств может привести к множеству общественных проблем, таких как снижение качества предоставляемых социальных услуг и, как следствие, волнения среди гражданского населения.

Во избежание данных явлений необходимо совершенствование механизма администрирования доходов. Кроме этого, следует использовать возможность получения дохода от использования бюджетных денег. Территориальным органам Федерального казначейства необходимо перейти в категорию новой реальности, чтобы так же, как и средства государственного бюджета, находящиеся на едином счете, средства региональных бюджетов работали. Это становится возможным при проведении непрерывного комплексного анализа исполнения бюджета, позволяющего своевременно выявлять причины недопоступления запланированных сумм и оперативно их устранять.

Pезультаты и обсуждение / Results and discussion. Доходная часть республиканского бюджета Кабардино-Балкарии за 2017 год составила 25 174,6 млн руб. Данный показатель ниже значения 2016 года на 1804,6 млн руб., или на $7 \%$, а также ниже показателя 2015 года на 562 млн руб., или на $2,2 \%$ (рис. 1).

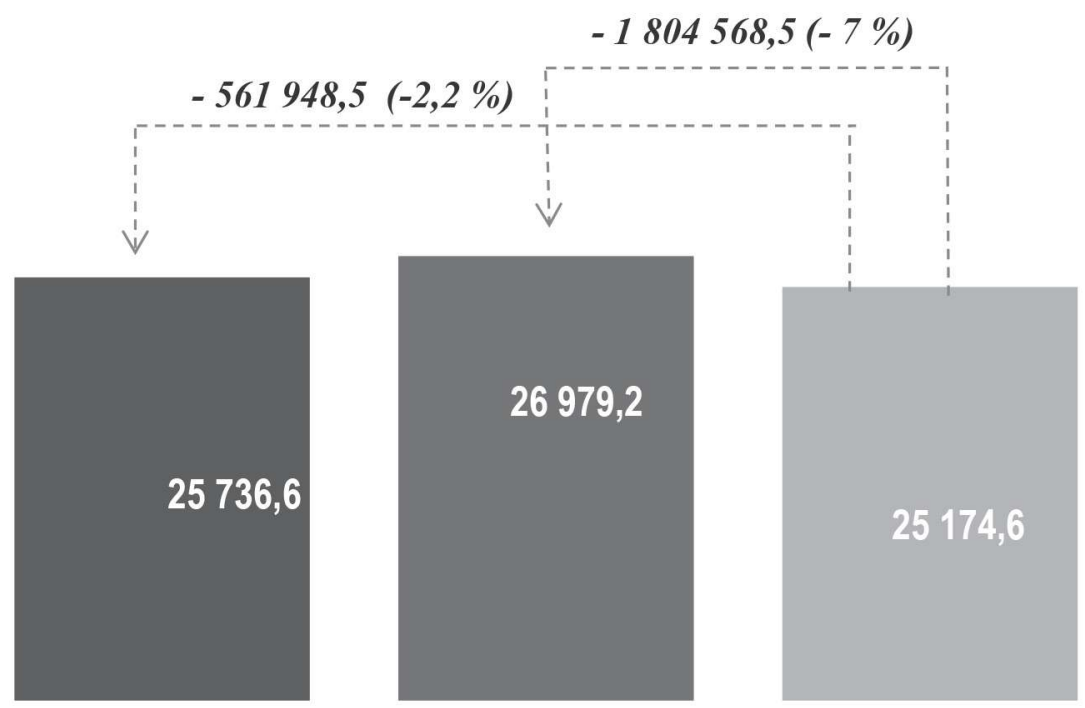

Рис. 1. Динамика доходов республиканского бюджета Кабардино-Балкарии за 2015-2017 гг., млн руб. 
Таблица

Динамика доходов республиканского бюджета Кабардино-Балкарии за 2015-2017 гг., млн руб.

\begin{tabular}{|c|c|c|c|c|}
\hline Наименование показателя & 2015 & 2016 & 2017 & $\begin{array}{c}\text { Темп роста } \\
\text { к 2015, \% }\end{array}$ \\
\hline дОхОДы & 25736,6 & 26979,2 & 25174,6 & 97,8 \\
\hline НАЛОГОВЫЕ & 10356,5 & 11082,8 & 9478,2 & 91,5 \\
\hline Налог на прибыль организаций & 943,7 & 1521,5 & 1790,8 & 189,8 \\
\hline НДФЛ & 2795,6 & 2941,5 & 2912,8 & 104,2 \\
\hline Акцизы & 4215,2 & 4300,5 & 2205,8 & 52,3 \\
\hline Акцизы на алкогольную продукцию & 2969,9 & 2624,3 & 848,6 & 28,6 \\
\hline $\begin{array}{l}\text { Доходы от уплаты акцизов на ГСМ (УФК Смолен- } \\
\text { ской области) }\end{array}$ & 1245,3 & 1676,1 & 1357,2 & 108,9 \\
\hline Налоги на совокупный доход & 411,8 & 467,7 & 502,6 & 122 \\
\hline Налоги на имущество & 1940,1 & 1794,8 & 1996,3 & 102,8 \\
\hline $\begin{array}{l}\text { Налоги, сборы и регулярные платежи за пользова- } \\
\text { ние природными ресурсами }\end{array}$ & 10,0 & 9,0 & 6,6 & 66 \\
\hline Государственная пошлина & 39,6 & 47,1 & 62,8 & 158,6 \\
\hline $\begin{array}{l}\text { Задолженность и перерасчеты по отмененным нало- } \\
\text { гам, сборам и иным обязательным платежам }\end{array}$ & 0,5 & 0,7 & 0,4 & 80 \\
\hline НЕНАЛОГОВЫЕ & 611,1 & 1164,4 & 345,1 & 56,5 \\
\hline $\begin{array}{l}\text { Доходы от использования имущества, находящегося } \\
\text { в государственной и муниципальной собственности }\end{array}$ & 47,9 & 68,7 & 52,7 & 110 \\
\hline Платежи при пользовании природными ресурсами & 11,9 & 14,5 & 1,9 & 15,9 \\
\hline $\begin{array}{l}\text { Доходы от оказания платных услуг (работ) и ком- } \\
\text { пенсации затрат государства }\end{array}$ & 207,6 & 222,4 & 226 & 108,9 \\
\hline $\begin{array}{l}\text { Доходы от продажи материальных и нематериаль- } \\
\text { ных активов }\end{array}$ & 51,9 & 131,8 & 47,9 & 92,3 \\
\hline Административные платежи и сборы & 0,6 & 0,7 & 0,5 & 83,3 \\
\hline Штрафы, санкции, возмещение ущерба & 260,5 & 346,3 & 367,7 & 141,1 \\
\hline БЕЗВОЗМЕЗДНЫЕ ПОСТУПЛЕНИЯ & 14768,9 & 14732,0 & 15351,4 & 103,9 \\
\hline $\begin{array}{l}\text { Дотации на выравнивание бюджетной обеспечен- } \\
\text { ности }\end{array}$ & 7962,1 & 7650,1 & 9237,9 & 116 \\
\hline $\begin{array}{l}\text { Дотации бюджетам на поддержку мер по обеспече- } \\
\text { нию сбалансированности бюджетов }\end{array}$ & 500,5 & 668,8 & 433,0 & 86,5 \\
\hline $\begin{array}{l}\text { Субсидии бюджетам бюджетной системы РФ (меж- } \\
\text { бюджетные суббсидии) }\end{array}$ & 3720,8 & 3870,7 & 3398,0 & 91,3 \\
\hline Субвенции бюджетам бюджетной системы РФ & 1799,5 & 1813,5 & 1793,0 & 99,6 \\
\hline Иные межбюджетные трансферты & 744,9 & 457,1 & 265,9 & 35,7 \\
\hline $\begin{array}{l}\text { Безвозмездные поступления от государственных } \\
\text { (муниципальных) организаций }\end{array}$ & 111,4 & 285,0 & 29,2 & 26,2 \\
\hline $\begin{array}{l}\text { Доходы бюджетов бюджетной системы РФ от воз- } \\
\text { врата бюджетами бюджетной системы РФ остатков } \\
\text { субсидий, суббвенций и иных межбюджетных транс- } \\
\text { фертов, имеющих целевое назначение, прошлых лет }\end{array}$ & 7,4 & 1,8 & 4,8 & 64,9 \\
\hline
\end{tabular}

*Составлено авторами на основе Законов об исполнении бюджета КБР за 2015-2017 г2. [1,2,3]. 
Структура доходной части республиканского бюджета Кабардино-Балкарии на протяжении всего исследуемого периода формировалась преимущественно за счет безвозмездных поступлений. Их доля являлась неизменно превалирующей, составляя в 2015 году 57,4 \%, в 2016 году $55 \%$, в 2017 - $61 \%$. Значительный удельный вес принадлежит и налоговым поступлениям, которые занимали в 2015 году 40,2 \%, в 2016 году - 41,1 \%, в 2017 году - 38 \%. Наименьшую долю в общем объеме доходов республиканского бюджета составляют неналоговые доходы, удельный вес которых был равен в 2015 году 2,4 \%, в 2016 году - 4,3\%, в 2017 году - 1,4 \%. (рис. 2).

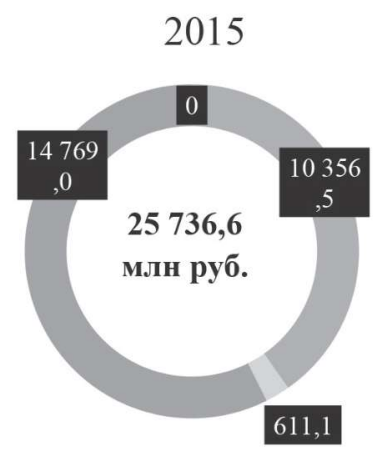

шалоговые доходы

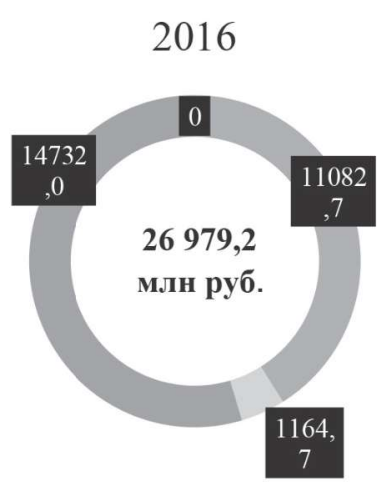

- Неналоговые доходы

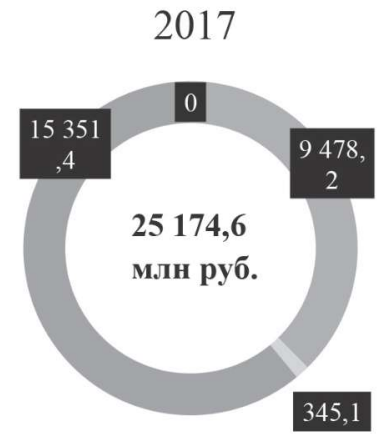

Безвозмездные поступления

Рис. 2. Формирование республиканского бюджета Кабардино-Балкарии по отдельным видам доходов за 2015-2017 гг., млн руб.

Безвозмездные поступления в республиканский бюджет Кабардино-Балкарии за 2017 год составили 15351,4 млн руб., продемонстрировав значительный прирост в размере 619,4 млн руб., или 4,2\% по сравнению с 2016 годом, в размере 582,4 млн. руб., или 3,9\%, по сравнению с 2015 годом. Рост данной статьи доходов сигнализирует о снижающейся самостоятельности республиканского бюджета и, соответственно, о непрерывном сокращении его собственных доходов.

Налоговые поступления республиканского бюджета Кабардино-Балкарии составили 9 478,2 млн руб. Суммарный объем данного вида доходов уменьшился на 1604525 тыс. руб., или на 14,5\%, по сравнению с результатом 2016 года, и также сократился на 878268 тыс. руб., или на $8,5 \%$, по сравнению с результатом 2015 года.

Основным фактором, повлиявшим на снижение общего объема налоговых доходов республиканского бюджета КБР, стало сокращение поступлений акцизов по подакцизным товарам, что, в свою очередь, явилось следствием массового отзыва лицензий у предприятий республики, производящих алкогольную продукцию. Так, в ноябре 2016 года глава Кабардино-Балкарии Юрий Коков заявил об остановке всех мощностей, производящих спиртосодержащую продукцию в связи с тотальной невозможностью контролировать легальность данного сегмента бизнеса. Таким образом, уменьшение поступлений данного вида дохода за исследуемый период составило в целом 47,7\% и привело в 2017 году к выпадению из бюджета 2 904,1 млн рублей [6].

Неналоговые доходы бюджета Кабардино-Балкарии в 2017 году составили 345,1 млн руб. Данный показатель ниже результата 2016 года на 819,3 млн руб., или на $30 \%$, и ниже результата 2015 года на 266 млн руб., или на 56,4\%. Объяснением данного снижения является недостаточное исполнение в 2017 году прогноза доходов по большинству статей неналоговых доходов в силу различных факторов. Например, недопоступление доходов от оказания платных услуг (работ) и компенсации затрат государства составило 51,8 млн руб. Этот факт является следствием того, 
что Министерству труда, занятости и социальной защиты Кабардино-Балкарии не удалось заключить договоры на оздоровление детей из близлежащих республик в БРДРЦ «Радуга». Таким же образом платежей при пользовании природными ресурсами из запланированных 11,1 млн руб. поступило всего лишь 1,9 млн руб., что было связано с уменьшением платы за размещение отходов производства и потребления и изменением Федерального закона от 10.01.2002 г. № 7-Ф3 «Об охране окружающей среды».

Отмечается также недопоступление вследствие неисполнения прогнозного плана приватизации государственного имущества, доходов от продажи материальных и нематериальных активов в размере 102,1 млн руб. Не удалось исполнить и прогноз по штрафам, санкциям и возмещению ущерба в связи с увеличением частоты использования 50-процентной скидки при уплате административных штрафов за нарушение законодательства Российской Федерации о безопасности дорожного движения в установленный срок [4].

Несмотря на сокращение общего объема доходов республиканского бюджета и непростую экономическую ситуацию в регионе, органам государственной власти Кабардино-Балкарской Республики совместными усилиями удалось сохранить положительную динамику по большинству доходных источников бюджета. Указанное стало возможным за счет реализации следующих мероприятий [6]:

- перевод в течение 2017 г. 194 объектов недвижимости на уплату налога на имущество организаций исходя из кадастровой стоимости, что обеспечило прирост доходов в размере 160,5 млн руб., или 9,9\%, по сравнению с предыдущим годом;

- применение целого комплекса мер принудительного взыскания в целях снижения роста задолженности по транспортному налогу, позволившее повысить уровень его собираемости с 50,2\% до 60,8 \%. В результате этого поступления транспортного налога в 2017 г. по сравнению с предыдущим годом увеличились в абсолютном выражении на 38,9 млн рублей, или на $23,1 \%$;

- проведение Комиссией Управления Федеральной налоговой службой РФ по КБР встреч с руководителями бюджетообразущих филиалов российских компаний в Кабардино-Балкарской Республике по вопросу обеспечения поступления налога на прибыль на уровне 2016 года. В результате этих встреч 117 организаций уменьшили убыток по сравнению с первоначально заявленной величиной на сумму 87,7 млн рублей и заявили дополнительную прибыль в размере 165,8 млн рублей. Проведенная работа позволила по итогам 2017 года выполнить годовой план по налогу на прибыль на 113,4 \% и превысить результат 2016 года на 269341 тыс. руб., или на 17,5\%;

- привлечение свыше 20 млн руб. дополнительных административных штрафов посредством мобилизации и повышения их собираемости.

Таким образом, анализ состава, динамики и структуры доходной части республиканского бюджета Кабардино-Балкарии позволил выявить ряд «хронических заболеваний» - снижение общего объема доходной части, сокращение доли собственных доходов и усиление зависимости от федеральной поддержки, снижение уровня исполнения прогнозов, растущий дефицит и т. д. Основной причиной этих проблем, как показало исследование, является повышенная чувствительность республиканского бюджета к сокращению поступлений акцизов на подакцизные товары. По устранению этого негативного фактора органы государственной власти республики принимают все необходимые меры. Так, активно прорабатывается вопрос по запуску алкоголепроизводящих предприятий - уже две организации получили лицензию на производство и реализацию крепкой алкогольной продукции. Также идет кропотливая работа уполномоченных органов по наращиванию стабильных доходных источников и совершенствованию налогового администрирования. На наш взгляд, данные мероприятия непременно будут увенчаны успехом и позволят укрепить и развить доходную часть республиканского бюджета Кабардино-Балкарии. 
Заключение/Conclusion. В заключение необходимо отметить, что пока будет формироваться налоговый потенциал региона, можно обратиться к современным казначейским технологиям исполнения бюджета по доходам, а также зарабатыванию с помощью размещения временно свободных остатков бюджетных ресурсов в разнообразные финансовые инструменты, например, банковские депозиты, сделки РЕПО. Так, по данным Федерального казначейства за 2017 год, государство заработало почти 83,0 млрд руб. Добиться этого поможет, на наш взгляд, цифровизация. Это одна из самых обсуждаемых сегодня тем. Казначейство России - самое продвинутое ведомство в сфере IT-технологий. Значительные результаты в этой области - это Единая информационная система в сфере закупок. По объему скопленной информации система содержит 350 терабайт, это big data, или «большие данные», ежегодный объем контрактов составляет 25 триллионов рублей.

Цифровизация открывает множество возможностей. Она обеспечивает прозрачность, степень которой в сфере закупок в России самая высокая в мире. Собрана вся информация о каждом государственном заказчике, о каждой закупке. Россия достигла значительных результатов в сфере управления закупками, прозрачности закупок и возможности контролировать эти закупки со стороны регулирующих органов и со стороны граждан.

Планируется перевод с 1 января 2019 года в электронный вид всех форм и способов размещения заказа. Однако эта электронная форма пока не цифровизация. То есть в настоящее время какие-то действия совершаются на бумаге, а потом информация размещается в электронной форме. В перспективе сами действия будут осуществляться путем электронного взаимодействия только через Единую информационную систему.

К 2020 году Федеральное казначейство должно стать полноценной платежной системой в России для упрощения и ускорения бюджетных расчетов. Необходимо перевести казначейскую систему на современные платежные технологии. Все многочисленные счета Казначейства в Банке России, необходимые для обслуживания клиентов, а это около 70 тысяч всевозможных видов счетов, будут переведены на баланс Казначейства. И должен быть открыт единый корреспондентский счет Казначейства в Центральном банке. Появляется огромное количество преимуществ.

Для достижения всего этого вначале следует оптимизировать нормативно-правовое регулирование. Далее необходимо осуществить такую реформу, ввиду того что она будет связана с перспективной платежной системой Банка России, с изменениями, которые проводятся в банковском секторе.

Казначейство должно использовать современные платежные технологии лучше тех, которые применяются в банковской сфере. Казначейство вместе с Национальной системой платежных карт (НСПК) и Фондом социального страхования провели в 33 регионах страны внедрение технологии перечисления средств на карты «Мир». В результате радикально уменьшается документооборот и транзакционные издержки. Фактически платежи стали проходить мгновенно, и получатели эту разницу чувствуют. День, два или три - это принципиальный вопрос для людей. Что касается платежной системы, следует стремиться к быстрым, мгновенным платежам. Как только обязательство возникло, платеж должен быть сразу, этот срок должен быть минимизирован.

Таким образом, Федеральное Казначейство будет преобразовано в платежную систему, причем эта трансформация произойдет в ближайшее время. В Бюджетный кодекс будут внесены поправки, которые сделают возможной работу системы казначейских платежей. Затем в 2019 году в Банке России будет открыт единый казначейский счет. С его помощью будет происходить обслуживание всех клиентов Казначейства. В 2020 году все счета, которые будут на тот момент у Казначейства в Банке России, будут переведены в само Казначейство, после чего оно начнет функционировать как полноценная платежная система.

Управление ликвидностью нового казначейского счета позволит начислять публично-правовым структурам проценты, которые будут переводиться на их счета, такая возможность должна появиться с 2021 года. 


\section{ЛИТЕРАТУРА И ИНТЕРНЕТ-РЕСУРСЫ}

1. Об исполнении республиканского бюджета КБР за 2017 год: Закон КБР от 08.06.2018. № 17-Р3 [Электронная версия]. URL: http://pravitelstvo.kbr.ru/oigv/minfin/npi/zakonodatelstva_i_podzakonnye_ normativnye_akty.php

2. Об исполнении республиканского бюджета КБР за 2016 год: Закон КБР от 09.06.2017. №1 8-Р3 [Электронная версия]. URL: http://pravitelstvo.kbr.ru/oigv/minfin/npi/zakonodatelstva_i_podzakonnye_ normativnye_akty.php

3. Об исполнении республиканского бюджета КБР за 2015 год: Закон КБР от 08.06.2016. № 30-Р3 [Электронная версия]. URL: http://pravitelstvo.kbr.ru/oigv/minfin/npi/zakonodatelstva_i_podzakonnye_ normativnye_akty.php

4. Пояснительная записка к годовому отчету об исполнении республиканского бюджета Кабардино-Балкарии [Электронная версия]. URL: http://pravitelstvo.kbr.ru/oigv/minfin/npi

5. Отчеты о начислении и поступлении налогов, сборов и иных обязательных платежей // Данные по формам статистической налоговой отчетности. Федеральная Налоговая Служба. URL: https://www.nalog.ru

6. Калашникова Е. Ю., Анимукова Д. М. Налоговые поступления как источник доходной части бюджета Российской Федерации // Молодой ученый. 2018. № 22. С. 414-417. URL: https://moluch.ru/ archive/208/50983

\section{REFERENCES AND INTERNET RESOURCES}

1. Ob ispolnenii respublikanskogo byudzheta KBR za 2017 god: Zakon KBR ot 08.06.2018. № 17-RZ [EHlektronnaya versiya]. URL: http://pravitelstvo.kbr.ru/oigv/minfin/npi/zakonodatelstva_i_podzakonnye_ normativnye_akty.php

2. Ob ispolnenii respublikanskogo byudzheta KBR za 2016 god: Zakon KBR ot 09.06.2017. № 18-RZ [EHlektronnaya versiya].URL:http://pravitelstvo.kbr.ru/oigv/minfin/npi/zakonodatelstva_i_podzakonnye_ normativnye_akty.php

3. Ob ispolnenii respublikanskogo byudzheta KBR za 2015 god: Zakon KBR ot 08.06.2016. № 30-RZ [EHlektronnaya versiya]. URL: http://pravitelstvo.kbr.ru/oigv/minfin/npi/zakonodatelstva_i_podzakonnye_ normativnye_akty.php

4. Poyasnitel'naya zapiska k godovomu otchetu ob ispolnenii respublikanskogo byudzheta Kabardino-Balkarii [EHlektronnaya versiya]. URL: http://pravitelstvo.kbr.ru/oigv/minfin/npi

5. Otchety o nachislenii i postuplenii nalogov, sborov i inyh obyazatel'nyh platezhej // Dannye po formam statisticheskoj nalogovoj otchetnosti. Federal'naya Nalogovaya Sluzhba. URL: https://www.nalog.ru

6. Kalashnikova E. YU., Animukova D. M. Nalogovye postupleniya kak istochnik dohodnoj chasti byudzheta Rossijskoj Federacii (Tax revenues as a source of revenue of the budget of the Russian Federation), Molodoj uchenyj, 2018, №22. P. 414-417. URL https://moluch.ru/archive/208/50983

\section{СВЕДЕНИЯ ОБ АВТОРАХ}

Савцова Анна Валерьевна, доктор экономических наук, доцент, кафедра финансов и кредита, Институт экономики и управления, ФГАОУ ВО «Северо-Кавказский федеральный университет». Е-mail: levandanna $a$ yandex.ru

Паценко Ольга Николаевна, кандидат экономических наук, кафедра финансов и кредита, Институт экономики и управления, ФГАОУ ВО «Северо-Кавказский федеральный университет». E-mail: olnik2004@mail.ru

Анимукова Диана Муаедовна, студент кафедры финансов и кредита, Институт экономики и управления, ФГАОУ ВО «Северо-Кавказский федеральный университет». E-mail: diana_animukova@mail.ru

\section{INFORMATION ABOUT AUTHORS}

Anna Savtsova, Doctor of Economics, associate Professor, Department of Finance and credit Institute of Economics and Management, North Caucasus Federal University. E-mail: levandanna@yandex.ru

Olga Patsenko, Candidate of Economic Sciences, Department of Finance and credit, Institute of Economics and Management, North Caucasus Federal University. E-mail: olnik2004@mail.ru

Diana Animukova, student of the Department of Finance and credit, Institute of Economics and management, North Caucasus Federal University. E-mail: diana_animukova@mail.ru 